\title{
Diagnóstico y manejo de mujeres con osteoporosis post-menopáusicas
}

\author{
Dres. Oscar Manuel Alba Mendoza*, Enrique Ardila Ardila**, William Onatra Herrera***, \\ Reina de Alayón****
}

\begin{abstract}
RESUMEN: Se analizan 64 pacientes postmenopáusicas de la Clínica de Climaterio del Hospital Materno Infantil y del Hospital San Juan de Dios de Bogotá con el fin de evaluar el grado de Osteoporosis y la respuesta al tratamiento. Para cumplir el primer objetivo se conformaron 5 grupos:

Grupo 0 o control con 20 pacientes menores de 20 años

Grupo 1: 5 pacientes 20 y 30 años.

Grupo 2: 6 pacientes entre 31 y 40 años.

Grupo 3: 21 pacientes entre 41 y 50 años.

Grupo 4: 23 pacientes entre 51 y 60 años.

Grupo 5: 8 pacientes mayores de 60 años.

Para el diagnóstico de Osteoporosis se dispone de marcadores plasmáticos como la PTH, Orteocalcina, Fosfatasa Alcalina, además, de los estudios radiológicos, radiografía de columna (TAC Densitometría de doble fotón). En este estudio aplicando la "T DE STUDENT" mostró diferencias significativas en los grupos 2 y 5 frente a los controles (P< 0.0.1) para la FSH, TSH, E2, PTH, Osteocalcina, Fosfatasa Alcalina y Fósforo Sérico. Valores de $(\mathrm{P}<001)$ en el calcio sérico y proteínas totales. No hubo diferencia significativa en el sérico y proteínas totales. No hubo diferencia significativa en el Fósforo Urinario. El índice de deformidad para radiografía de columna mostró una clara tendencia de lesión a nivel de T7 y L1.
\end{abstract}

Para el objetivo No. 2 se conformaron 4 grupos terapéuticos:

Grupo 1: Fluoruro de Sodio + Calcio $(\mathrm{N}=12)$

Grupo 2: Terapia Secuencial Hormonal $(N=11)$

Grupo 3: Calcio $(\mathbf{N}=4)$

Grupo 4: Placebo $(\mathrm{N}=8)$

Un corte a los 6 meses muestra en el grupo 1 cambios significativos en la Fosfatasa Alcalina y Osteocalcina (P<0.01), Grupo 2: disminución del Calcio Sérico $(P<0.01)$ y aumento de la Fosfatasa Alcalina $(P<0.001)$. En el grupo 3 no hubo variación. Con esta información el tratamiento con Fluoruro de Sodio + el Calcio se presenta como una alternativa a la terapia hormonal de sustitución en pacientes postmenopáusicas.

PALABRAS CLAVES: Osteoporosis, Osteocalcina, Fosfatasa Alcalina, Fluoruro de Sodio.

SUMMARY: 64 post-menopausic patients of the climateric clinic of the Materno Infantil and San Juan de Dios Hospitals Bogotá werw studied in order to evaluate the osteoporosis degree and the answer to the treatment.

For the first objetive, 5 groupes were conformed:

Group $O$ or control with 20 patients younger than 20 years old.

Group 1: 5 patients 20-30 years old

Group 2: 4 patients between 31-40 years old

Group 3: 21 patients 41-50 year old

Group 4: 23 patients 51-60 years old

Group 5: 8 patients older than 60 years old

For osteoporosis diagnostic, there are plasmatic markers such as PTH, osteocalcin, alkaline phosphatase, in addition to the radiological studies, spine radiographs (densitometric TAC of double "Foton"). In this study, applying the STUDENT T shows significant differences in groups 2 and 5 in front of controls (P 0.01) for the FSH, TSH, E2, PTH, osteocalcin alkalin "phosphatase" and serum phosphorus. Values of $P \quad 0.01$ in serum calcium and total protein. There was no significative difference in the urinary phosphorus. The index of deformity for spine radiography shows a clear tendency of lesión in T7 N L1 levels.

For the objetive No. 2, 4 therapeutic groups were conformed: Group 1: sodium fluoride $+\operatorname{calcium}(N=12)$

Group 2: Therapy hormonal sequence

Group 3: Calcium $(\mathbf{N}=4)$

Group 4: Placebo $(N=8)$

An cutting at 6 months shows in the group 1 a significative change in alkalin phosphatase and osteocalcin (P 0.01) and increase in phosphate. Group 3 has no change. With this information, the treatment with sodium fluoride + calcium is presented as an alternative to hormonal therapy of replacement in post-menopausic patients.

KEY WORDS: Osteoporosis, osteocalcin, alkaline phosphatase. 


\section{Introducción}

La osteoporosis es una entidad clínica que se puede definir como una reducción en la masa ósea que incrementa la susceptibilidad a las fracturas. Definirla de manera más precisa es difícil debido a que el rango de masa ósea varía de acuerdo con el tipo de población estudiado y a que no se puede separar de manera categórica grupos de personas con baja masa ósea (1).

En promedio, la masa ósea tiende a disminuir después de la tercera década en todas las poblaciones estudiadas; de tal manera que la pérdida ósea puede ser considerada como un fénomeno universal de envejecimiento $(1,2)$.

Además, existen factores de tipo genético, ambiental y en el caso de la osteoporosis postmenopáusica (OPPM), factores hormonales sexuales estrechamente relacionados que parecen jugar un papel importante en su inicio (3). Existen factores de riesgo descritos y condiciones asociadas que pueden mejorar o empeorar su evolución (2).

El manejo de esta entidad se puede realizar a dos niveles: preventivo y terapéutico.

La OPPM está siendo reconocida cada vez más en el ámbito médico; no sólo por su alta incidencia que se calcula en un $30 \%$ de las mujeres postmenopáusicas en los países desarrollados (4), sino también por los altos gastos en salud tanto directos como indirectos que puede ocasionar (5).

En Colombia, a la fecha, no existen estudios detallados sobre la osteoporosis en general. Como datos generales podemos decir que las fracturas ocupan el quinto lugar dentro de las diez primeras causas de egresos hospitalarios en la población mayor de 45 años (6); lo cual nos da una tibia idea sobre la verdadera magnitud del problema.

Por todo lo anterior, aunado al interés por el estudio de las patologías del metabolismo fosfo-cálcico que se han adelantado en la sección, hemos querido acometer esta interesante patología en un estudio de tipo experimental que aborde elementos tanto de tipo diagnóstico como de tratamiento y curso clínico de la OPPM en un grupo seleccionado de pacientes. Creemos que este estudio es pionero en Colombia y puede llegar a ser de gran valor para análisis futuros que se hagan sobre el tema.

Es de prever que en nuestra población existen factores de riesgo suficientes para el establecimiento de este tipo de patología de tal modo que puede ser tan importante como muchas entidades frecuentes que estamos acostumbrados a manejar de manera rutinaria como médicos en la actualidad.

\section{Material y métodos}

El diseño de investigación utilizado contempló un estudio de tipo prospectivo. En un protocolo previo se especificó un organigrama en donde se prevé una serie de tiempos iniciales $(t=0)$ y de seguimiento cada seis meses hasta los dos años de duración del estudio $(t=1, t=2, t=3$ y $t=4)$.

\footnotetext{
* Residente IV Endocrinología

** Profesor Asociado Sección de Endocrinología. Departamento de Medicina Interna

*** Profesor Asistente. Unidad Endocrinología, ginecología Departamento de Obstetricia y Ginecología.

**** Docente Especial Sección de Endocrinología, Universidad Nacional de Colombia.
}

Es preciso anotar que tan sólo se alcanzaron a realizar determinaciones bioquímicas, hormonales y radiológicas al momento de inclusión de los sujetos al estudio $(\mathrm{t}=0)$ y en un control a los seis meses $(t=1)$. Los datos así obtenidos serán sujeto de análisis y discusión más adelante.

Se incluyeron un total de 64 pacientes escogidas de la consulta de la clínica de climaterio del Instituto Materno Infantil y remitidas de otros servicios del Hospital San Juan de Dios.

También hubo un grupo de 24 mujeres premenopáusicas, en su mayoría estudiantes de medicina de la facultad, que sirvieron como grupo de comparación de algunas variables iniciales o basales. Los criterios de inclusión para las pacientes eran mujeres en menopausia con por lo menos seis meses de amenorrea esporádica o quirúrgica, con niveles de FSH y/o estradiol en rango menopáusico, que no tuvieran causas conocidas de osteoporosis secundaria y que no estuvieran recibiendo tratamiento de suplencia hormonal y/o medicaciones que se sepa alteren el metabolismo mineral.

A todas las pacientes se les entrevistó y examinó acorde a un modelo de historia clínica previamente establecido en un protocolo en donde se contemplan aspectos sobre todo relacionados con los criterios de inclusión. De esta historia se obtuvieron algunos datos usados como variables tales como el índice de masa corporal (IMC $\mathrm{K} / \mathrm{m}^{2}$ ), la edad de la paciente en años y el tiempo de evolución de la menopausia (en años).

El único factor de riesgo usado como variable fue el de la ingesta habitual de calcio; por ser de fácil cuantificación y por no ser tan controvertido, aunque algunos lo cuestionan (7). Esta ingesta fue determinada a través de una encuesta nutricional en la que colaboró para su obtención el Departamento de Nutrición de la Facultad de Medicina de la Universidad Nacional, adonde eran enviadas las pacientes para la elaboración del respectivo formulario. Otros factores tales como paridad, cigarrillo, alcohol, etc., no se incluyeron para efecto de análisis dado a que no se conocen muy bien aún y a que no son fácilmente cuantificables.

Una vez hecha la entrevista, se citaba a la paciente en ayunas al laboratorio (8:00 a.m.) para tomar una muestra de sangre la cual se centrifugaba inmediatamente para obtener suero y congelarlo para los análisis ulteriores; también una muestra de orina basal, entendida esta como la orina de las dos últimas horas de ayuno, para lo cual se le decía a la paciente que desocupara su vejiga a las 6:00 a.m. Posteriormente se solicitaba una radiografía de columna dorsolumbar lateral, la cual fue tomada con la misma técnica en un aparato convencional de rayos X en el Instituto Materno Infantil.

Este mismo esquema se aplicó a las mujeres premenopáuscias del grupo control excepto la solicitud de la radiografía.

Al momento de ingreso al estudio $(t=0)$, se determinaron calcio, fósforo y creatinina en suero y orina. El calcio se determinó por el método de espetroscopia de absorción atómica en un aparato Perkin Elmer disponible en Ingeominas para el presente estudio, a donde se llevaban las muestras después de diluirlas 20:1 para el suero y 10:1 para orina con una solución de óxido de lantano. La creatinina y el fósforo se determinaron por medio de kits comerciales que emplean métodos colorimétricos convencionales (Merck). 
A partir de estas mediciones se obtuvieron valores de excreçión basal de calcio por orina, sea como la simple medida del mismo, sea como expresado como un indice calcio/creatinina ( $\mathrm{mg} / \mathrm{mg}$ ). También se calcularon el umbral de reabsorción de fosfato (TRP) y su máximo umbral (TmP) acorde al nomograma de Bijvoet (8).

Otros parámetros de química sanguínea medidos fueron proteínas totales-albúmina y fosfatasa alcalina con kits comerciales colorimétricos (Merck).

Las determinaciones hormonales basales consistieron de FSH, estradiol (E2), TSH, PTH-M y osteocalcina (BGP). Todas ellas con kits comerciales para radioinmunoensayo marca DPC excepto la osteocalcina con la que se usó de marca CIS. La totalidad de las determinaciones se corrieron por duplicado en el contador gamma de la sección de endocrinología.

Para efectos del estudio radiológico, se analizó para cada una de las pacientes una radiografía lateral de la columna dorsolumbar midiendo con regla milimetrada la altura anterior (ha), media $(\mathrm{hm})$ y posterior $(\mathrm{hp})$ de cada una de las vértebras desde T5 hasta L5. Con estas medidas se establecen relaciones entre las diferentes alturas con el objeto de determinar un cierto grado de deformidad conformado así (Figura 1):

Deformidad en cuña grado $1=\mathrm{ha} / \mathrm{hp}<0.85>0.75$

Deformidad en cuña grado $2=\mathrm{ha} / \mathrm{hp}<0.75$

Deformidad bicóncava grado $1=\mathrm{hm} / \mathrm{hp}<0.85>0.75$

Deformidad bicóncava grado $2=\mathrm{hm} / \mathrm{hp}<0.75$

Deformidad de aplastamiento $1=\mathrm{hp} / \mathrm{hp}$ (adyacente)

$<0.85>0.75$

Deformidad de aplastamiento $2=\mathrm{hp} / \mathrm{hp}($ adyacente $)>0.75$

Estos criterios fueron descritos inicialmente por Riggs de la Clínica Mayo (9) y se describen frecuentemente en la literatura sobre todo para determinar la rata de fracturas o deformidades nuevas en determinado período de tiempo durante un estudio.

Este método sólo nos permite establecer "categorías" o rangos de deformidades haciéndolo poco accesible a análisis estadísticos más precisos. Por ello hemos ideado una modificación que permita "cuantificar" el grupo de deformidad más que categorizarlo y es asi como hemos obtenido un índice de deformidad, el cual resulta de relacionar el grado de deformidad, cualquiera que sea (grado 1 ó 2), con el número total de vértebras que es un número constante de 13, obteniéndose un valor numérico para cada deformidad según sea el caso, el cual al sumarlo da un puntaje total por cada paciente. Por ejemplo:

Una paciente con tres deformidades en cuña grado 1 tendrá: $(3 \times 1) \div 13=0.23$ y con dos deformidades bicóncavas grado 2 tendrá: $(2 \times 2) \div 13=0.30$, obteniendo un índice de deformidad total de 0.53 .

En un sujeto normal este índice será de cero, puesto que las relaciones de las diferentes alturas siempre darán mayores de 0.85 y por tanto no habría deformidades de ningún tipo.

Una vez incluidas de manera definitiva las pacientes, se asignaban al azar en uno de los siguientes cuatro grupos de tratamiento:

Grupo 1: Fluoruro de sodio ( $40 \mathrm{mg} /$ día $)+$ carbono de calcio (un gramo/día).

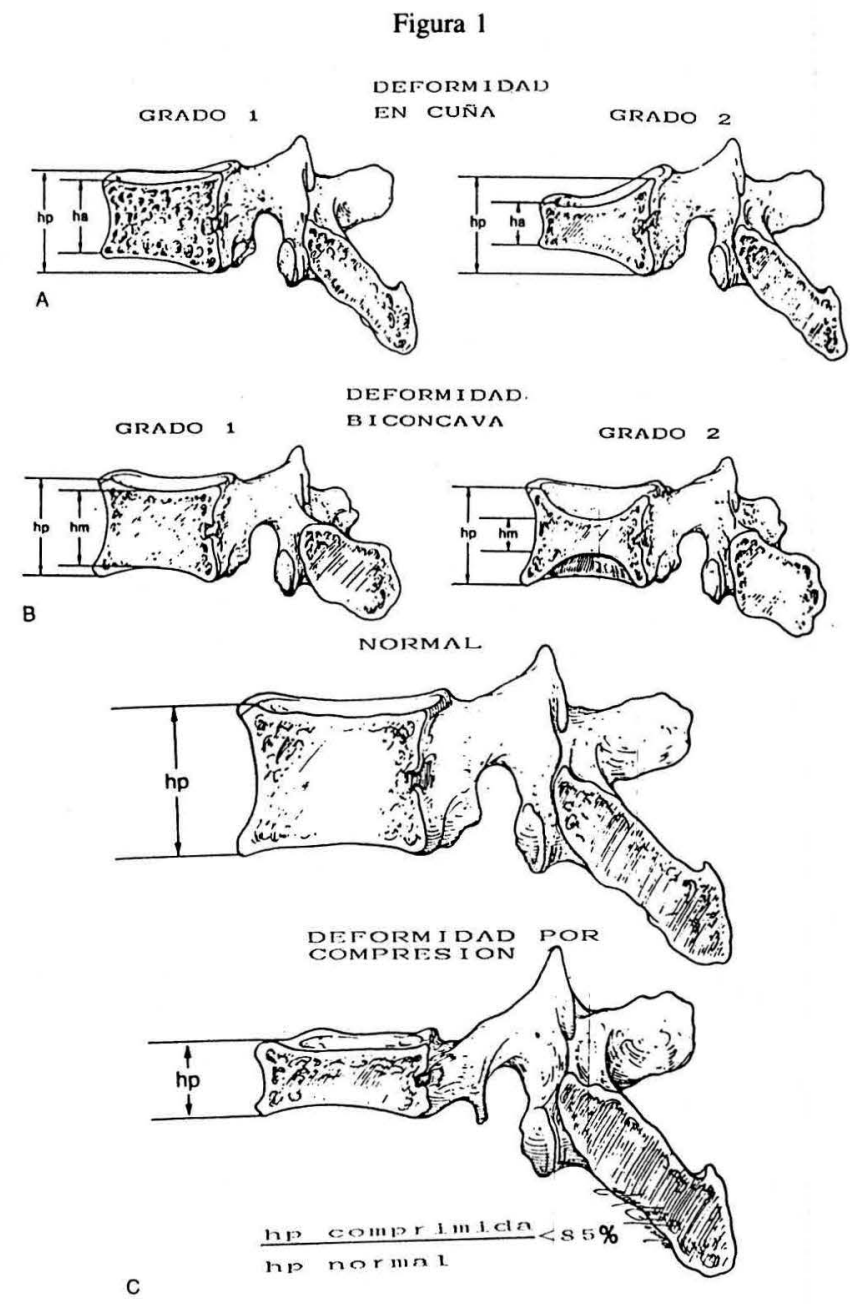

Clasificación de las fracturas vertebrales: (A): Fractura en cuña: En una fractura grado 1, la altura anterior (ha) es del $75 \%$ al $85 \%$ de la altura posterior (hp). En una grado 2 es menor del $75 \%$. (B): Fractura bicóncava: En una fractura grado 1 la altura media $(\mathrm{hm})$ es del $75 \%$ al $85 \%$ de la posterior (hp). En una grado 2 es menor del 75\%. (C) Fractura por aplastamiento: En este tipo de fractura la altura posterior hp es menor del $85 \%$ de la altura posterior adyacente.

Grupo 2: Estrógeno + Progesterona (2 mg de valerianato de estradiol durante 21 días asociado en una misma tableta a $0.5 \mathrm{mg}$ de norgestrel durante 10 días) + carbonato de calcio (un gramo).

Grupo 3: Carbonato de calcio (un gramo).

Grupo 4: Placebo.

La designación al azar consistió en pedirle a la paciente decir un número de 1 a 20 . Si decía un número par menor de 10 se asignaba al grupo uno, si era par mayor de 10 al dos, si era impar menor de 10 al tres y si era impar mayor de 10 al cuatro.

Se emplearon marcas comerciales para el fluoruro de sodio (OSSIN de laboratorios Grunenthal) y para la suplencia hormonal secuencial (Progyluton de laboratorios Schering alemana).

El carbonato de calcio se preparó en forma de polvo para diluir en agua según una fórmula ideada en el departamento 
de farmacia de la Facultad de Ciencias de la Universidad Nacional; al igual que las tabletas de placebo que consistieron de una preparación de harina-azúcar.

Las determinaciones hechas en el primer corte de control y seguimiento a los seis meses $(t=1)$, consistieron de calcio en sangre y orina; así como fosfatasa alcalina, osteocalcina y PTH-M en suero, todo con las mismas especificaciones ya descritas.

Los análisis estadísticos consistieron de pruebas paramétricas clásicas como el error estándar para todas las medias; una dócima " $t$ " de student para la comparación de medias entre dos grupos; análisis. de la varianza de una sola vía (ANOVA) para comparaciơn de.medias entre varios grupos y un análisis de regresión a través del coeficiente de correlación " $r$ " de Pearson para-medir el grado de dependencia entre dos variables (generalmente aleatorias). Todas ellas con su respectivo nivel de significancia estadístico ("p"). Estas pruebas están descritas en libros de bioestadística básica $(10,11)$.

Los grupos se dividieron acorde a la edad (etáreos) de la siguiente manera:

Grupo 0: Controles-premenopáusicas $(\mathrm{n}=24)$

Grupo I: Pacientes menores de 30 años $(n=5)$

Grupo II: Pacientes de 31 a 40 años $(n=6)$

Grupo III: Pacientes de 41 a 50 años $(n=21)$

Grupo IV: Pacientes de 51 a 60 años $(n=23)$

Grupo V: Pacientes Mayores de 60 años $(n=8)$

\section{Resultados}

Las pacientes en su mayoría fueron tomadas de la Clínica de Climaterio del Instituto Materno Infantil, la cual tiene algún tiempo de creada y en la que por primera vez se aborda el estudio de la OPPM, gracias al protocolo diseñado por nosotros.

A esta clínica son remitidas las pacientes que por causas naturales o quirúrgicas estén en menopausia para una valoración médica y ginecológica detallada; además de evaluar otros aspectos tales como sicológicos, nutricionales, etc. De este gran grupo de pacientes se seleccionaron tan sólo las que reunían los criterios de inclusión ya descritos.

No todas las pacientes referían sintomatología relacionada con indicios de osteoporosis tales como dolor lumbar por fracturas, etc. En una gran proporción fueron asintomáticas. Muchas de ellas acudían a la consulta motivadas por la preocupación que genera esta entidad clínica. Todas las pacientes nuevas recibían una charla informativa y educativa la primera semana de cada mes.

Otro grupo de pacientes fue remitido a la consulta de endocrinología por otros servicios del Hospital San Juan de Dios a los que se invitó a participar en este tratajo con la remisión de pacientes a través de charlas académicas sobre el tema.

El grupo de mujeres premenopáusicas sanas fueron en su gran mayoría estudiantes de medicina de la facultad de medicina, con el inconveniente de ser un grupo muy homogéneo como grupo etáreo.

Se obtuvieron datos bioquímicos y hormonales en un total de 64 pacientes los cuales no tuvieron ningún costo. De este total regresaron a control con su respectiva radiografía 47 pacientes. La radiografía era costeada por cada una de ellas. Es posible que la causa de deserción de las pacientes restantes haya sido el económico entre otros, dado el costo de la radiografía o a no estar suficientemente motivadas para continuar con este tipo de estudio el cual busca dentro de sus objetivos concientizarlas acerca de la prevención de la OPPM.

Los resultados al inicio del estudio $(\mathrm{t}=0)$ de las distintas variables de cada una de las pacientes se muestran en la Tabla 3; los de las mujeres sanas premenopáusicas en la Tabla 2.

Es necesario aclarar que por motivos de tipo técnico y económico no hay homegeneidad absotula en el número (n) de cada una de las variables para todos los sujetos; pero consideramos de todas maneras que para efectos del análisis estadístico se asegura un buen número (n) para las distintas variables.

Los valores promedio $( \pm \mathrm{ES})$ de las distintas variables medidas tanto en el grupo de pacientes como un total, como en el grupo de mujeres sanas premenopáusicas con su respectiva comparación y significancia estadística, se muestran en la Tabla 3.

Llama la atención de entrada, encontrar diferencias estadísticamente significativas de las medias de casi todas las variables estudiadas.

En cuanto a las variables del metabolismo fosfocálcico, observamos que, dentro de los límites considerados normales, las pacientes tienden a tener valores ligeramente más altos de calcio sérico $(10.4 \pm 0.1$ vs. $10.1 \pm 0.1 \mathrm{p}<$ $0.01)$.

Es frecuente encontrar reportes en la literatura médica de estos temas, que las mujeres con OPPM tienden a tener una mayor excreción de calcio urinario el cual se toma incluso como un índice de resorción ósea (12); nosotros, al contrario, observamos una menor excreción urinaria de calcio con alta significancia estadística $(6.3 \pm 0.5$ vs. $9.6 \pm 13$, $\mathrm{p}<0.001$ ). Este hecho lo podríamos explicar a través de la PTH con la cual se correlaciona de manera inversa y significativa como se discutirá posteriormente.

En la Figura 2 observamos graficados los valores promedio del calcio urinario por grupos de edad con los valores más bajos en el IV y V $(\mathrm{F}=2.91, \mathrm{p}<0.05)$. En la Tabla 4 se aprecian los valores por grupos de edad del calcio sérico, con una ANOVA significativo $(\mathrm{F}=5.8, \mathrm{p}<0.01)$.

Los valores de fósforo sérico muestran cómo son significativamente más bajos en las pacientes $(2.9 \pm 0.05$ vs. 3.1 $\pm 0.07, p<0.001$ ), aunque también dentro de los límites considerados como normales. No hubo diferencias en los valores de excreción de fósforo urinario al igual que en los valores de reabsorción de fosfato (TRP); pero sí hubo una pequeña diferencia en los valores del umbral máximo de reabsorción (TmP) que tienden a estar disminuidọs en las pacientes $(2.18 \pm 0.08$ vs. $2.38 \pm 0.14, \mathrm{p}<0.10)$. Todo ello podría traducir, hasta cierto punto, una función renal intacta tanto en las pacientes como en las mujeres premenopáusicas, igualmente, a que no hay mayor compromiso de estos parámetros en la OPPM como sí ocurre en otras afecciones del metabolismo mineral como la litiasis renal cálcica en donde sus alteraciones juegan un papel fisiopatológico importante.

Finalmente, verificamos una buena correlación entre estas medidas de absorción urinaria del fósforo (TRP y TmP) 
Tabla 2

VALORES INDIVIDUALES DE LAS VARIABLES MEDIDAS EN LAS MUJERES DEL GRUPO CONTROL

\begin{tabular}{|c|c|c|c|c|c|c|c|c|c|c|c|c|c|c|c|}
\hline $\mathbf{n}$ & $\begin{array}{l}\text { Edad } \\
\text { años }\end{array}$ & $\begin{array}{l}\text { I.M.C. } \\
\mathbf{k} / \mathbf{m}^{2}\end{array}$ & $\begin{array}{l}\text { Calcio } \\
\text { Sérico } \\
\mathrm{mg} / \mathrm{dL}\end{array}$ & $\begin{array}{c}\text { Calcio } \\
\text { Orina } \\
\text { mg/dL }\end{array}$ & $\begin{array}{l}\text { Fósforo } \\
\text { Sérico } \\
\text { mg/dL }\end{array}$ & $\begin{array}{r}\text { Fósforo } \\
\text { Orina } \\
\mathrm{mg} / \mathrm{dL}\end{array}$ & TRP & $\begin{array}{l}\text { TmP } \\
\text { TFG }\end{array}$ & $\begin{array}{r}\text { Prot. } \\
\text { Total } \\
\text { g/L }\end{array}$ & $\begin{array}{r}\text { Fosfat. } \\
\text { Alcaln } \\
\mathbf{u} / \mathbf{L}\end{array}$ & $\begin{array}{l}\text { PTH-M } \\
\text { ng/mL }\end{array}$ & $\begin{array}{r}\text { BGP } \\
\mathbf{n g} / \mathbf{m L}\end{array}$ & $\begin{array}{c}\text { FSH } \\
\mathrm{mU} / \mathrm{mL}\end{array}$ & $\begin{array}{l}\text { Estrad. } \\
\text { pg/mL }\end{array}$ & $\begin{array}{c}\text { TSH } \\
\mathbf{u U T} / \mathbf{m L}\end{array}$ \\
\hline 1 & 19 & 25.4 & 11.0 & 31.7 & 2.9 & 50 & 0.77 & 2.3 & 6.8 & 15 & 0.5 & 3.6 & 8 & 150 & 3.4 \\
\hline 2 & 21 & 24.1 & 10.3 & 4.8 & 2.9 & 43 & 0.66 & 1.9 & 8.6 & 15 & 0.4 & 1.2 & 9 & 310 & 3.3 \\
\hline 3 & 27 & 21.9 & 8.5 & 6.1 & 4.0 & 25 & 0.94 & 4.7 & 7.6 & 20 & 0.8 & 5.0 & 9 & 260 & 3.5 \\
\hline 4 & 22 & 23.9 & 10.0 & 7.8 & 2.9 & 30 & 0.83 & 2.5 & 8.4 & 15 & 0.7 & 4.0 & 11 & 300 & 3.5 \\
\hline 5 & 21 & 22.6 & 10.0 & 4.8 & 3.0 & 28 & 0.75 & 2.3 & 7.4 & 15 & 0.5 & 4.0 & 11 & 310 & 3.4 \\
\hline 6 & 21 & 20.3 & 10.0 & 14.3 & 3.4 & 30 & 0.88 & 3.4 & 8.4 & 15 & 0.6 & 3.0 & 9 & 750 & 3.6 \\
\hline 7 & 21 & 21.9 & 10.0 & 19.0 & 3.2 & 25 & 0.88 & 3.1 & 7.2 & 25 & 1.0 & 2.8 & 2 & 140 & 3.6 \\
\hline 8 & 22 & 18.8 & 10.3 & 4.0 & 3.5 & 20 & 0.90 & 3.5 & 7.5 & 10 & 0.9 & 2.8 & 2 & 110 & 3.6 \\
\hline 9 & 20 & 19.9 & 10.0 & 6.8 & 3.3 & 50 & 0.63 & 2.1 & 7.5 & 10 & 0.66 & 2.8 & 3 & 90 & 3.4 \\
\hline 10 & 21 & 22.6 & 9.9 & 3.2 & 3.0 & 48 & 0.70 & 2.1 & 7.8 & 10 & 0.4 & 1.2 & 3 & 180 & 3.6 \\
\hline 11 & 21 & 17.0 & 9.9 & 11.9 & 3.5 & 43 & 0.67 & 2.3 & 7.8 & 10 & 0.6 & 2.8 & 3 & 180 & 1.1 \\
\hline 12 & 22 & 18.0 & 9.1 & 19.5 & 2.9 & 31 & 0.75 & 2.2 & 8.2 & 20 & 0.6 & 2.8 & 2 & 160 & 0.6 \\
\hline 13 & 20 & 19.8 & 9.9 & 9.4 & 2.6 & 69 & 0.46 & 1.2 & 7.8 & 10 & 0.8 & 3.2 & 2 & 140 & 1.0 \\
\hline 14 & 21 & 20.8 & 9.0 & 4.7 & 3.9 & 59 & 0.59 & 2.3 & 7.5 & 10 & 0.8 & 3.6 & 2 & 110 & 2.1 \\
\hline 15 & 21 & 20.6 & 9.8 & 9.3 & 3.0 & 38 & 0.68 & 2.0 & 7.2 & 10 & 0.9 & 2.5 & 2 & 85 & 2.5 \\
\hline 16 & 21 & 23.5 & 10.6 & 9.3 & 2.9 & 55 & 0.73 & 2.0 & - & 10 & 0.8 & - & 14 & 75 & 2.4 \\
\hline 17 & 21 & 23.5 & - & 4.8 & 2.9 & 40 & 0.82 & 2.3 & - & 10 & 0.4 & - & 16 & 110 & 2.3 \\
\hline 18 & 20 & 22.2 & 10.8 & 8.5 & 2.9 & 62 & 0.75 & 2.1 & - & 8 & 0.2 & - & 16 & 190 & 2.5 \\
\hline 19 & 24 & 20.6 & 10.7 & 11.6 & 2.8 & 50 & 0.71 & 1.9 & - & 12 & 0.3 & - & 15 & 230 & 2.6 \\
\hline 20 & 21 & 19.5 & 10.3 & 9.4 & 3.1 & 55 & 0.72 & 2.2 & - & 10 & 0.8 & - & 17 & 280 & 2.3 \\
\hline 21 & 19 & 22.9 & 10.8 & 6.0 & 3.1 & 70 & 0.62 & 1.9 & - & 14 & 1.2 & - & 13 & 240 & 2.1 \\
\hline 22 & 21 & 20.8 & 10.6 & 13.1 & 2.8 & 40 & 0.79 & 2.2 & - & 15 & 0.5 & - & 7 & 180 & 1.9 \\
\hline 23 & 20 & 22.2 & 10.7 & 6.7 & 2.9 & 58 & 0.66 & 1.9 & - & 15 & 0.7 & - & 4 & 180 & 3.3 \\
\hline 24 & 20 & 18.3 & 10.9 & 3.7 & 3.2 & 50 & 0.74 & 2.3 & - & 8 & 0.5 & - & 5 & 90 & 3.1 \\
\hline
\end{tabular}

Tabla 3

VALORES PROMEDIO ( \pm ES) DE LAS DISTINTAS VARIABLES EN CONTROLES Y PACIENTES

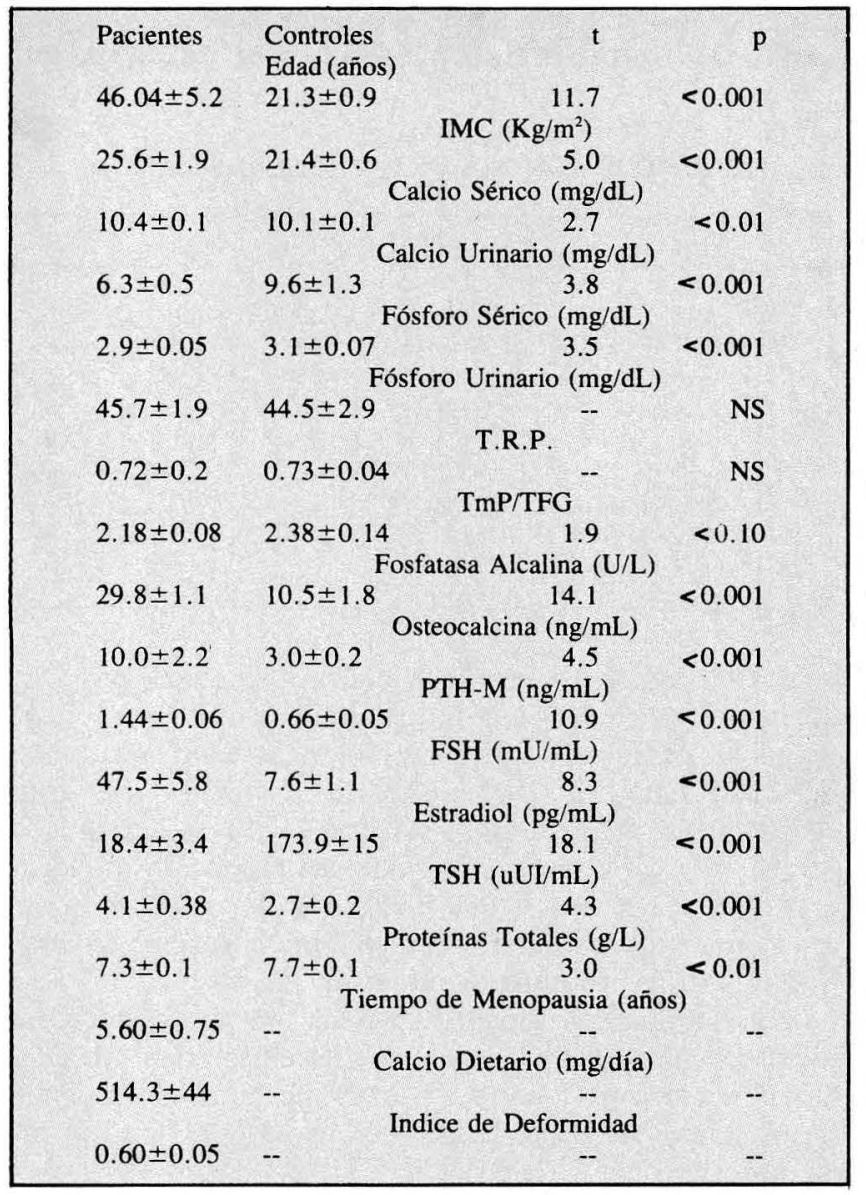

Figura 2

CALCIO URINARIO DISTRIBUCION POR GRUPO DE EDAD

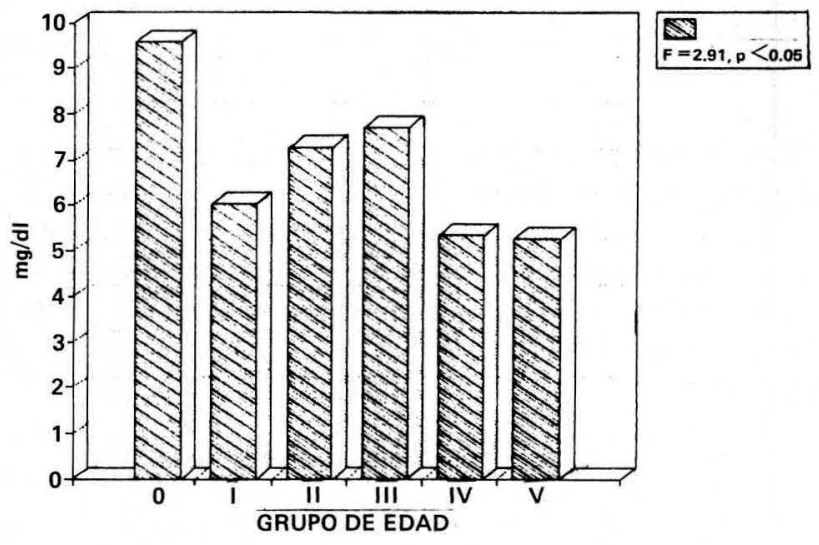

Tabla 4

DISTRIBUCION POR GRUPOS DE EDADES DEL CALCIO SERICO

\begin{tabular}{|lcccccc|}
\hline & $\mathbf{0}$ & I & II & III & IV & V \\
\hline $\mathbf{n}$ & 23 & 5 & 6 & 20 & 23 & 8 \\
$\mathbf{x}$ & 10.1 & 10.1 & 10.3 & 10.4 & 10.4 & 10.5 \\
ES & 0.1 & 0.3 & 0.4 & 0.1 & 0.1 & 0.2 \\
\hline
\end{tabular}

$\mathbf{F}=5.8$

$\mathrm{p}<0.01$

según se aprecia en la Tabla 5 . Se ve cómo las variables que mejor se correlacionan con ellas son obviamente el fósforo sérico y urinario. Existe también una buena correlación entre ellas $(r=0.86, p<0.001)$. 
Tabla 5

REGULACION FOSFOCALCICA

\begin{tabular}{|cccc|}
\hline & $\begin{array}{c}\text { Calcio } \\
\text { Sérico }\end{array}$ & $\begin{array}{c}\text { Fósforo } \\
\text { Sérico }\end{array}$ & $\begin{array}{c}\text { Fósforo } \\
\text { Urinario }\end{array}$ \\
\hline TRP & -0.24 & 0.54 & -0.70 \\
& $\mathrm{p}<0.20$ & $\mathrm{p}<0.001$ & $\mathrm{p}<0.001$ \\
\hline
\end{tabular}

0.86

$\mathrm{p}<0.001$

\begin{tabular}{cccc} 
TmP & -0.35 & 0.75 & -0.58 \\
& $p<0.02$ & $p<0.001$ & $p<0.001$ \\
\hline
\end{tabular}

Con respecto a la hormona paratiroidea (PTH), de mucha importancia en la regulación del metabolismo fosfocálcico (13), encontramos una diferencia estadísticamente importante con valores mayores para las pacientes $(1.44 \pm 0.06$ vs. $0.66 \pm 0.05, p<0.001)$. Hecho per se interesante y que de alguna manera deja entrever un posible rol fisiopatológico en la OPPM sea como causa o muy seguramente como consecuencia de las alteraciones que ocurren en la misma y que aún permanecen por ser dilucidadas.

En la Figura 3 observamos los valores promedio de la PTH distribuidos por grupos de edades en donde se aprecia cómo los valores más altos corresponden a los grupos de mayor edad (III, IV y V). El análisis de la varianza (ANOVA) da un valor altamente significativo $(F=9.37, p<$ 0.001 ). Este hecho debe tener alguna relación con los valores de excreción del calcio urinario, que como vimos, es más disminuido en estos grupos de edad. Sabemos que una de las importantes acciones fisiológicas de PTH es aumentar la reabsorción tubular distal del calcio por un mecanismo activo muy bien descrito (14).

En la Tabla 6 observamos algunos coeficientes de correlación (r) de la PTH con respecto a otras variables medidas.

Es interesante notar cómo nuevamente se encuentra una significancia estadística de la PTH con respecto a la edad de las pacientes $(r=0.34, p<0.01)$, corroborando los hallazgos que se describieron anteriormente; además existió una correlación significativa con el tiempo de evolución de

Figura 3

PARATOHORMONA (PTH)

DISTRIBUCION POR GRUPO DE EDAD

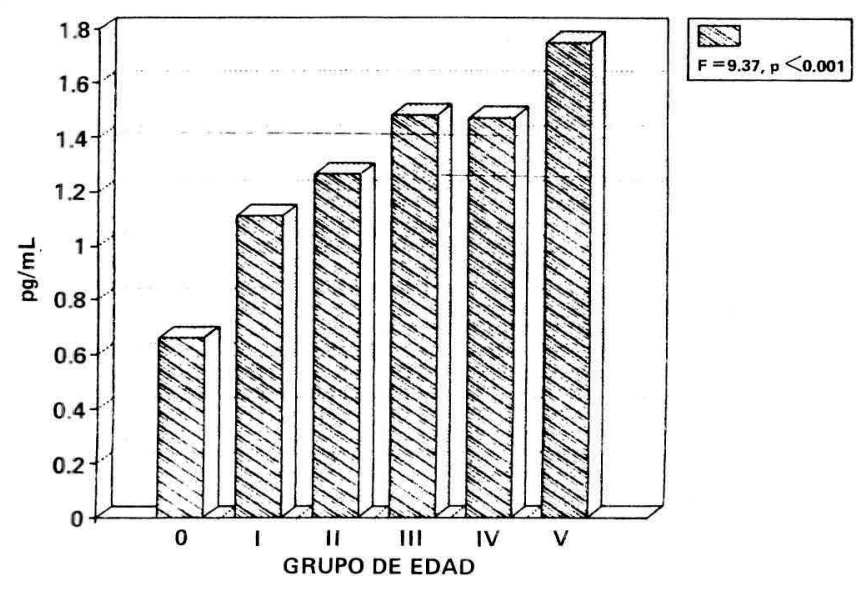

la menopausia $(r=0.26, p<0.10)$. También se encuentra una correlación significativa y esperada entre la PTH y el calcio sérico $(r=0.30, p<0.02)$ así como con el calcio urinario $(\mathrm{r}=0.27, \mathrm{p}<0.05)$ evidenciándose una relación fisiológica entre estos parámetros (13).

Se verifica también la conocida acción fosfatúrica de la PTH (15), dada por una correlación significativa y positiva con el fósforo urinario $(r=0.28, p<0.05)$ y negativa con su umbral de reabsorción (TRP) $(\mathrm{r}=0.30, \mathrm{p}<0.05)$.

Un hallazgo de bastante interés en el presente estudio fue el del comportamiento de la PTH con respecto a los valores de fosfatasa alcalina al encontrarlas correlacionadas de manera inversa $(r=-0.23, p<0.10)$. Hoy se sabe que la PTH en su interacción con las células osteoprogenitoras del linaje osteoblástico inhibe la producción de fosfatasa alcalina por parte de las mismas, un hecho que está siendo investigado con interés en la actualidad (16).

Los marcadores de recambio óseo, osteocalcina y fosfatasa alcalina, se encuentran significativamente distintos en las pacientes con respecto a las mujeres premenopáusicas sanas (para la osteocalcina $10.0 \pm 2.2$ vs. $3.0 \pm 0.2, \mathrm{p}<0.001$; y para la fosfatasa alcalina $29.8 \pm 1.1$ vs. $10.5 \pm 1.8, \mathrm{p}<0.001$ ); lo cual podría validar su papel como marcadores del recambio óseo ya que ambos son producidos por células del linaje osteoblástico (17) aunque su papel preciso en los mecanismos de formación ósea permanecen por ser dilucidados (18).

Dicho recambio óseo estaría por tanto aumentado en las mujeres con OPPM acorde a lo encontrado en los diferentes y numerosos trabajos de investigación sobre este tema y sería una constante fisiopatológica en esta entidad.

Tabla 6

COEFICIENTES DE CORRELACION DE LA PTH

\begin{tabular}{|lrrrr|}
\hline & $\mathbf{r}$ & $\mathbf{t}$ & $\mathbf{p}$ & $\mathbf{n}$ \\
\hline Edad & 0.34 & 2.81 & $<0.01$ & 63 \\
Tiempo de menopausia & 0.26 & 1.97 & $<0.10$ & 63 \\
Calcio sérico & -0.30 & 2.42 & $<0.02$ & 63 \\
Calcio urinario & -0.27 & 2.20 & $<0.05$ & 63 \\
Fósforo urinario & 0.28 & 2.02 & $<0.05$ & 49 \\
TRP & -0.30 & 2.11 & $<0.05$ & 49 \\
Fosfatasa alcalina & -0.23 & 1.90 & $<0.10$ & 63 \\
Indice de deformidad & 0.28 & 1.21 & NS & 47 \\
Calcio dietario & -0.10 & - & NS & 38 \\
& & & & \\
\hline
\end{tabular}

En la Figura 4 vemos graficados los valores promedio de la osteocalcina según los distintos grupos de edad encontrándose los valores más altos en los grupos de edad intermedia II y III (31 a 50 años) y los más bajos en el grupo $\mathrm{V}$ ( $>$ 60años), con un ANOVA algo significativo $(\mathrm{F}=1.94$, $\mathrm{p}<0.10$ ). Tal vez ello signifique una relativa insuficiencia osteoblástica a medida que transcurren los años aunque de todas maneras los valores son siempre superiores con respecto al grupo de mujeres premenopáusicas.

En la Figura 5 vemos graficados los valores promedio de la fosfatasa alcalina según los diferentes grupos de edad; aquí encontramos cómo los valores más altos corresponden a los grupos de mayor edad con un ANOVA mucho más significativo que el anterior $(\mathrm{F}=17, \mathrm{p}<0.001)$. 
Figura 4

OSTEOCALCINA (BGP)

DISTRIBUCION POR GRUPO DE EDAD

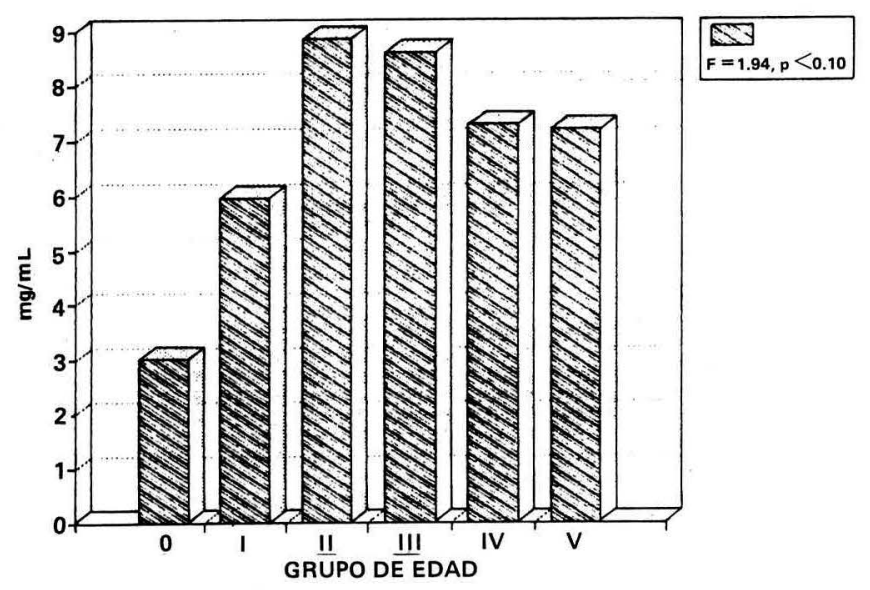

Figura 5

FOSFATASA ALCALINA DISTRIBUCION POR GRUPO DE EDAD

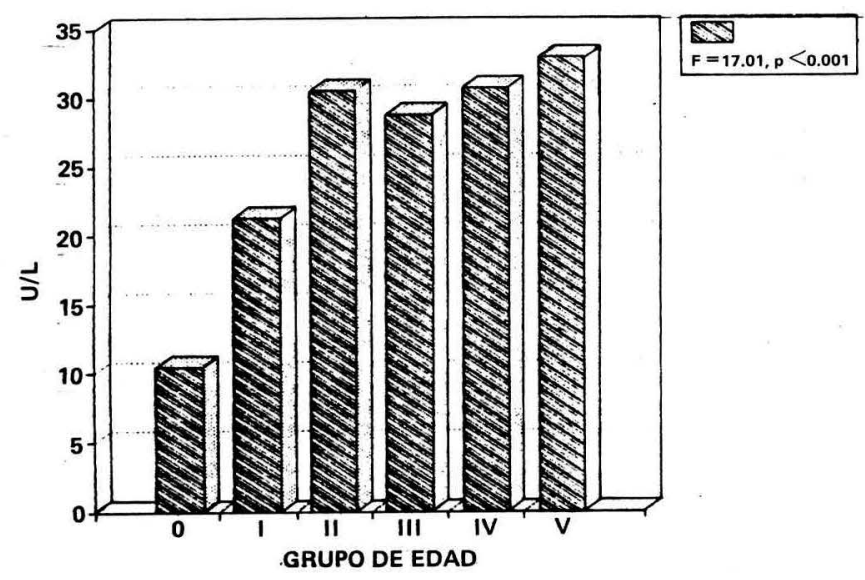

Estos dos hallazgos anteriores los consideramos de gran interés puesto que ambos tipos de marcadores siempre son mayores en los grupos de las pacientes con respecto al de las mujeres premenopáusicas, indicando quizá unos mecanismos de recambio óseo "intactos" en las pacientes con OPPM pese a su edad.

En la Tabla 7 se muestran los análisis de correlación de la nsteocalcina con respecto a otras variables. Son de interés la correlación inversa con la FSH $(\mathrm{r}=-0.31, \mathrm{p}<0.05)$ y la correlación positiva con la TSH $(r=0.36, p<0.02)$. Este último es interesante puesto que incluso se llegaron a detectar varios casos de hipotiroidismo como se aprecia en la tabla de valores individuales (Tabla 1) y que estaría en contra de lo encontrado por otros autores que han estudiado este tema más específicamente, en donde se encuentra una correlación negativa de la osteocalcina con respecto al estatus hormonal tiroideo, más específicamente con los estados de hiperfunción tiroidea (19).

En la Tabla 8 se muestran los análisis de correlación de la fosfatasa alcalina con respecto a otras variables. Son de interés nuevamente la correlación inversa con la FSH ( $\mathrm{r}=-$
$0.24, \mathrm{p}<0.10)$ y positiva, aunque un poco menos significativa con la TSH $(r=0.22, \mathrm{p}<0.20)$.

No tenemos explicación para el hallazgo, en ambos casos, de la correlación inversa con la FSH, puesto que no existe ningún tipo de correlación de estos marcadores con el estradiol (E2) según se aprecia en las tablas.

El índice de deformidad vertebral tuvo un rango que varió desde un valor mínimo de 0.08 hasta un valor máximo de 1.46, con un valor promedio de $0.60 \pm 0.05$.

En la Figura 6 se aprecia una distribución de frecuencias para cada una de las vértebras deformadas en las pacientes,

Tabla 7

COEFICIENTES DE CORRELACION DE LA BGP

\begin{tabular}{|rrrrr|}
\hline & $\mathbf{r}$ & $\mathbf{t}$ & $\mathbf{p}$ & $\mathbf{n}$ \\
\hline TSH & 0.36 & 2.73 & $<0.02$ & 51 \\
FSH & -0.31 & 2.44 & $<0.05$ & 62 \\
Indice de deformidad & 0.20 & 1.16 & NS & 47 \\
Calcio urinario & -0.19 & 1.49 & NS & 62 \\
Calcio sérico & -0.15 &.-- & NS & 62 \\
Fosfatasa alcalina & 0.19 & $\ldots-$ & NS & 62 \\
PTH & 0.15 & $\ldots-$ & NS & 62 \\
Tiempo de menopausia & -0.15 & -- & NS & 62 \\
Edad de la paciente & 0.01 & $\ldots-$ & NS & 62 \\
Estradiol & -0.14 & -- & NS & 51 \\
\hline
\end{tabular}

Tabla 8

COEFICIENTES DE CORRELACION DE LA FOSFATASA ALCALINA

\begin{tabular}{|rrrrr|}
\hline & $\mathbf{r}$ & $\mathbf{t}$ & $\mathbf{p}$ & $\mathbf{n}$ \\
\hline PTH & -0.23 & 1.90 & $<0.10$ & 63 \\
FSH & -0.24 & 1.87 & $<0.10$ & 60 \\
TSH & 0.22 & 1.59 & $<0.20$ & 52 \\
Edad de la paciente & 0.22 & 1.80 & $<0.10$ & 63 \\
Tiempo de menopausia & 0.13 & $\ldots-$ &.-- & 61 \\
Indice de deformidad & 0.05 & $\ldots-$ & -- & 47 \\
Calcio sérico & 0.14 & $\ldots-$ & -- & 63 \\
TmP & 0.16 & -- & -- & 47 \\
Estradiol & 0.06 & -- & -- & 52 \\
\hline
\end{tabular}

Figura 6

DISTRIBUCION DE FRECUENCIAS DE LAS DEFORMIDADES VERTEBRALES

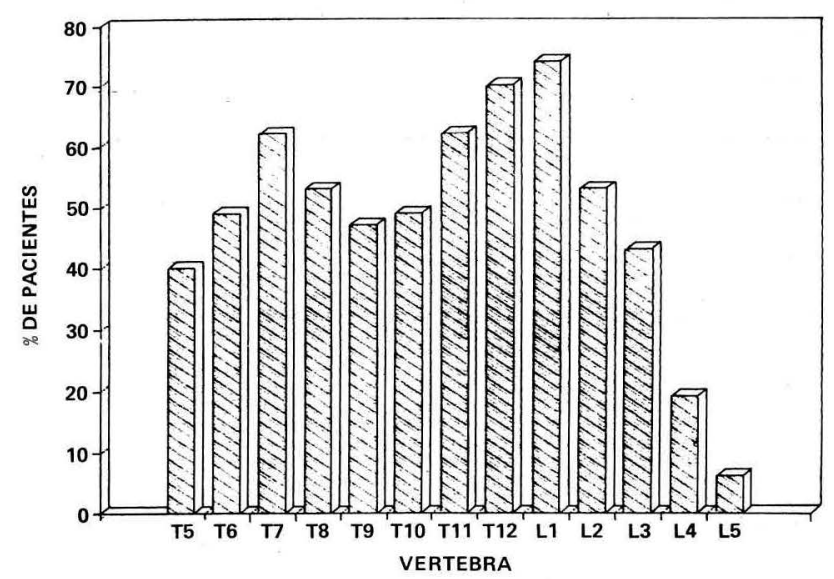


siendo las más comprometidas T7 (62\%), T11 (62\%), T12 (70\%) y L1 (74\%).

En la Figura 7 se grafican las sumatorias de las deformidades de cada una de la vértebras. Se observa una tendencia a cierta "deformibilidad" hacia T7 en las torácicas y L1 en las lumbares. Una posible explicación teórica biomecánica de este hallazgo podría ser la de que hacia L1 recae en gran proporción el centro de gravedad para la postura erecta y la bipedestación.

Esto debe motivarnos a hacer más precisiones en un futuro y valdría la pena correlacionar no sólo esta deformibilidad vertebral, sino también el índice de deformidad en sí mismo con otras medida densitométricas que en la actualidad por razones de tipo técnico y económico no poseemos.

En la Figura 8 vemos graficados los valores promedio del índice de deformidad por grupos de edad. Se observa cómo este es mayor en los grupos de mayor edad, especialmente el V, como es de esperar, con una buena significancia estadística por el ANOVA $(\mathrm{F}=5.44, \mathrm{p}<0.01)$. En vista de que tres pacientes del grupo 1 desertaron del estudio, no se tuvo en cuenta para este análisis.

Figura 7

LOCALIZACION DE LAS FRACTURAS VERTEBRALES

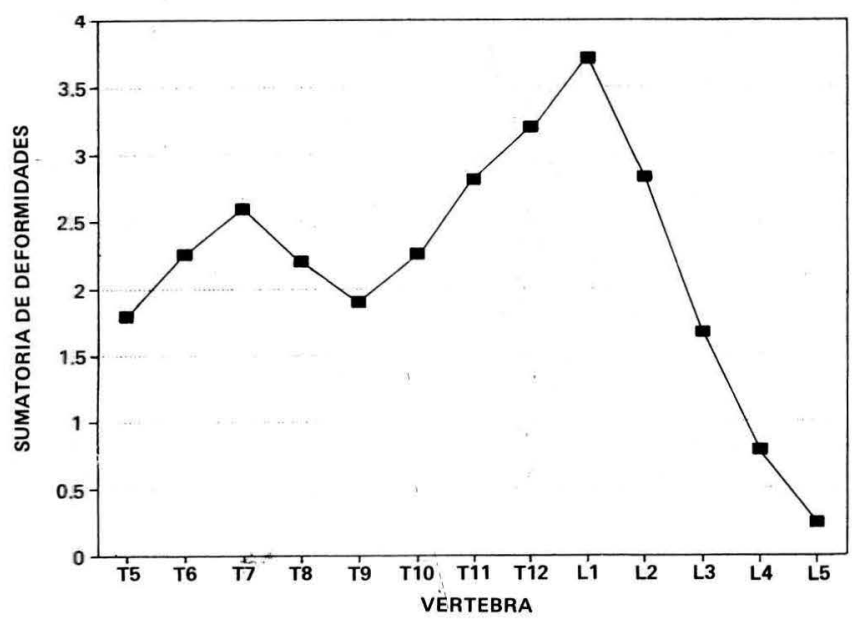

Figura 8

INDICE DE DEFORMIDAD DISTRIBUCION POR GRUPO DE EDAD

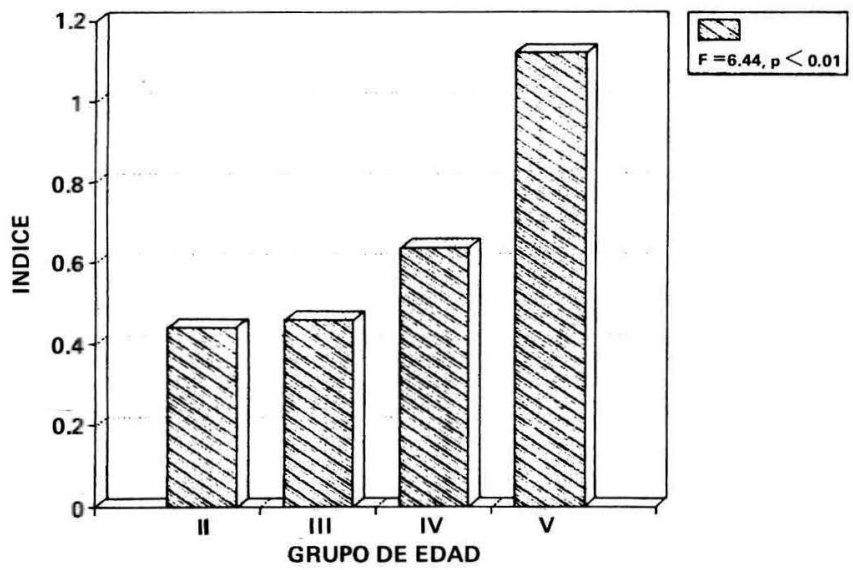

En la Tabla 9 se aprecia el coeficiente de correlación del índice de deformidad con respecto a otras variables. Es llamativo el encontrado de manera inversa con el calcio urinario $(r=-0.41, p<0.01)$ e igualmente con el calcio sérico $(\mathrm{r}=-0.31, \mathrm{p}<0.05)$. Podrían significar un mecanismo de defensa del organismo frente a la enfermedad, con una excreción por la orina y una movilización por el hueso reducidas ante una pérdida progresiva de hueso en el que posiblemente esté involucrada la PTH. Como era lo esperado, hubo una buena correlación del índice de deformidad con respecto a la edad de la paciente y al tiempo de evolución de la menopausia $(\mathrm{r}=0.34, \mathrm{p}<0.01$ y $\mathrm{r}=0.27$, $\mathrm{p}<0.10$ respectivamente) .

Tabla 9

COEFICIENTES DE CORRELACION DEL INDICE DE DEFORMIDAD

\begin{tabular}{|lrccc|}
\hline & $\mathbf{r}$ & $\mathbf{t}$ & $\mathbf{p}$ & $\mathbf{n}$ \\
\hline Edad & 0.34 & $2.5<0.01$ & 47 \\
Calcio urinario & -0.41 & $2.6<0.01$ & 47 \\
Calcio sérico & -0.31 & $2.2<0.05$ & 47 \\
Tiempo de menopausia & 0.27 & $1.9<0.10$ & 47 \\
Fósforo sérico & 0.23 & 1.0 & NS & 47 \\
BGP & 0.20 & 1.1 & NS & 46 \\
PTH & 0.18 & 1.0 & NS & 47 \\
IMC & -0.14 & 0.9 & NS & 47 \\
FSH & -0.13 &.- & NS & 47 \\
TSH & 0.06 &.- & NS & 47 \\
Calcio dietario & -0.13 &.- & NS & 38 \\
Fosfatasa alcalina & 0.05 & -- & NS & 47 \\
Proteínas totales & -0.10 & -- & NS & 47 \\
\hline
\end{tabular}

Es interesante notar que no hubo ninguna correlación del índice de deformidad con respecto a la PTH $(r=0.18, p<N S)$.

Esta hormona se ha considerado tradicionalmente como "resorbedora" de huesos pero últimamente se le está estudiando y entendiendo mejor su posible papel como factor "trófico" óseo (20). Tampoco hubo ninguna correlación de este índice con la TSH $(r=0.06, p<$ NS), hormona cuyo nivel refleja la función tiroidea y cuyo estatus, especialmente el de hiperfunción, interfiere de manera directa en la fisiología ósea (21); aunque hay que anotar que más bien se detectaron bastantes casos de hipofunción con la simple determinación de niveles basales de TSH.

Los marcadores de menopausia FSH y estradiol se comportaron dentro de lo esperado tanto en las mujeres premenopáusicas sanas como en la pacientes y hacían parte de los criterios de inclusión de estas últimas. Hubo entonces una significativa diferencia entre las pacientes con respecto a las mujeres premenopáusicas tanto para la FSH $(47.5 \pm 5.8$ vs. $7.6 \pm 1.1, \mathrm{p}<0.001)$ como para el estradiol $(18.4 \pm 3.4$ vs. $173.9 \pm 15, \mathrm{p}<0.001)$.

En la Figura 9 apreciamos la distribución de los valores promedio de la FSH por grupos de edades. Se observa cómo los valores más altos corresponden a los grupos de pácientes más jóvenes con un valor estadísticamente muy significativo $(\mathrm{F}=6.5, \mathrm{p}<0.001)$. Este hallazgo puede significar que la paciente más joven posee unos mecanismos de respuesta hipofisiarios más intactos.

En la Figura 10 se aprecia la distribución de los valores promedio del estradiol por grupos de edades. Los valores 
de estradiol son más altos entre más joven sea la persona, indicando quizá una mejor función ovárica en estos grupos de edades.

En la Tabla 10 se aprecian los coeficientes de correlación de las proteínas totales con respecto a alguna variable. Es llamativa la correlación inversa y significativa encontrada con la reabsorción tubular máxima de fosfato $(\mathrm{TmP})(\mathrm{r}=$ $0.32, \mathrm{p}<0.05)$ y la correlación positiva con el calcio urinario $(r=0.27, p<0.05)$.

Figura 9

F.S.H.

DISTRIBUCION POR GRUPO DE EDAD

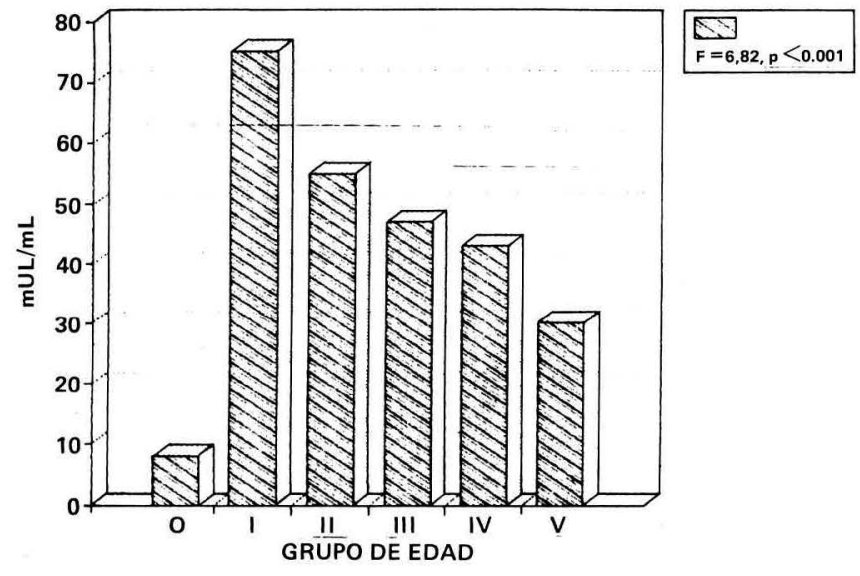

Figura 10

ESTRADIOL (E2)

DISTRIBUCION POR GRUPO DE EDAD

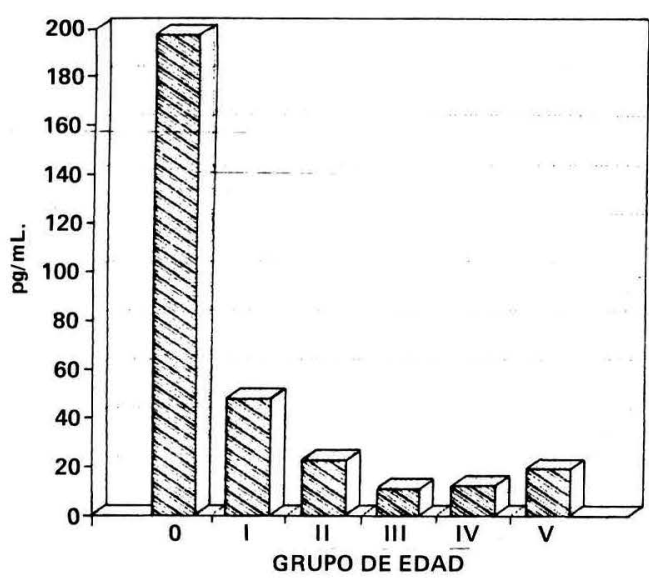

$\prod_{F=16.8, p}<0.001$

La encuesta nutricional se pudo realizar en 38 pacientes. El valor promedio del calcio ingerido de manera habitual es bajo $(514.3 \pm 44 \mathrm{mg} / \mathrm{día})$ con un rango de 91 a $121.3 \mathrm{mg} /$ día. Esto nos demuestra que al menos en este grupo de estudio, la ingesta de calcio está por debajo de los requerimientos establecidos a nivel internacional para las mujeres postmenopáusicas, que son de $1.500 \mathrm{mg} /$ día (7). Que ello signifique un factor de riesgo para el desarrollo de la OPPM en nuestras pacientes es cuestionable puesto que no encontramos ningun tipo de correlación de esta ingesta habitual de calcio con ninguna otra variable como se ve en
Tabla 10

COEFICICIENTES DE CORRELACION DE LAS PROTEINAS TOTALES

\begin{tabular}{|lrrrr|}
\hline & $\mathbf{r}$ & $\mathbf{t}$ & $\mathbf{p}$ & $\mathbf{n}$ \\
\hline TmP & -0.32 & 2.28 & $<0.05$ & 47 \\
Calcio urinario & 0.27 & 2.13 & $<0.05$ & 61 \\
IMC & 0.16 & -- & NS & 61 \\
Calcio dietario & -0.13 & -- & NS & 36 \\
Indice de deformidad & -0.10 & -- & NS & 47 \\
\hline
\end{tabular}

Tabla 11

COEFICIENTES DE CORRELACION DEL CALCIO DIETARIO

\begin{tabular}{|lrccc|}
\hline & $\mathbf{r}$ & $\mathbf{t}$ & $\mathbf{p}$ & $\mathbf{n}$ \\
\hline Indice de deformidad & -0.13 & --- & NS & 38 \\
Calcio urinario & -0.01 & -- & NS & 38 \\
Calcio sérico & 0.08 & -- & NS & 38 \\
PTH & -0.10 & -- & NS & 38 \\
Proteínas totales & -0.13 & --- & NS & 36 \\
\hline
\end{tabular}

la Tabla 11. Aunque puede ser que realizar este tipo de cálculos sea difícil y que para corroborar o descartar el papel del calcio en la dieta como factor de riesgo haya que emplear un tipo de estudio prospectivo a largo plazo como el empleado en otro trabajo (22) en donde se demostró que sí lo es.

En la Tabla 12 se aprecian los resultados obtenidos en los valores de calcio sérico, calcio urinario, PTH-M, osteocalcina y fosfatasa alcalina tanto al inicio $(\mathrm{t}=0)$ como a los seis meses del primer corte de seguimiento $(t=1)$ en los cuatro diferentes grupos de tratamiento empleados, con su respectiva significancia estadística para cada una de las variables.

En el grupo 1 (fluoruro de sodio + calcio) quedaron incluidas inicialmente 13 pacientes, de las cuales una se excluyó por presentar efectos secundarios al fluoruro dados por sensación de "entumecimiento" de las extremidades inferiores especialmente de los pies, síntoma descrito frecuentemente (23); otras dos desertaron del estudio sin saberse la causa.

En el grupo 2 (terapia secuencial hormonal + calcio) quedaron incluidas inicialmente 16 pacientes, de las cuales hubo cinco deserciones por razones no conocidas. Algunas pacientes de este grupo preséntaron sangrado espontáneo el cual fue valorado por un ginecólogo del Instituto Materno Infantil y en ningún caso hubo reporte de patología anormal.

En el grupo 3 (calcio) quedaron incluidas inicialmente seis pacientes, de las cuales hubo dos deserciones. En todos los casos hubo una buena tolerancia y aceptabilidad de la preparación usada.

En el grupo 4 (placebo) quedaron incluidad diez pacientes de las cuales desertaron dos.

Los resultados encontrados en el grupo 1 (fluoruro de sodio + calcio) muestran un aumento significativo en ambos tipos de marcadores de recambio óseo tanto en la osteocalcina (de $5.8 \pm 0.9$ a $9.5 \pm 1.7, p<0.001)$ como en la fosfatasa alcalina (de $30 \pm 1.9$ a $43 \pm 1.8, \mathrm{p}<0.001$ ). Esto podría estar indicando un aumento en el recambio óseo y por consiguiente en la formación de hueso estimulado por el fluoruro, verificando así lo encontrado por otros grupos 
Tabla 12

VALORES DE LAS DISTINTAS VARIABLES AL INICIO DEL ESTUDIO $(t=0) Y$ SEIS MESES DESPUES DE INICIADO UN TRATAMIENTO ESPECIFICO $(t=1)$

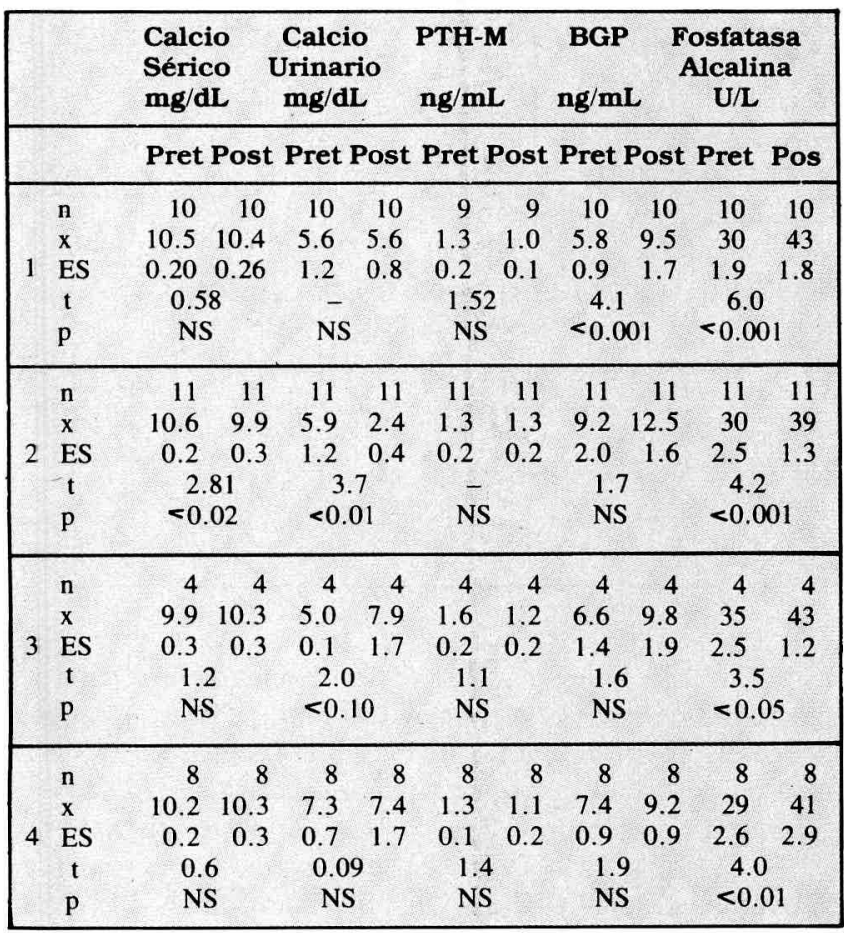

(24). Al fluoruro se le reconoce desde hace tiempo como una sustancia que induce formación ósea por mecanismos no del todo aclarados (25), aunque últimamente se dice que su efecto sería mediado por factores de crecimiento, específicamente IGF-1 (somatomedina C) (26).

Los resultados encontrados en el grupo 2 (terapia secuencial hormonal + calcio) muestran una disminución significativa en la excreción del calcio urinario (de 5.951.2 a $2.40 .4, p \quad 0.01$ ) y un aumento significativo en los valores de la fosfatasa alcalina (de $30 \pm 2.5$ a $39 \pm 1.3, p \quad 0.001)$. La excreción urinaria de calcio ha sido considerada como un índice de resorción ósea y su disminución a un tratamiento específico de tipo anti-resortivo (por ejemplo estrógenos) un reflejo de la disminución de aquel (27). Paradójicamente hubo un aumento en uno de los marcadores de recambio óseo (fosfatasa alcalina), lo cual no es fácil de explicar. Es preciso anotar que empleamos una terapia secuencial, más que estrogénica pura, en la cual el componente progestágeno podría estar contribuyendo a un aumento en la formación de hueso, como se ha evidenciado con la progesterona la cual induce un aumento en la frecuencia de activación ósea $(27,28)$. De cualquier manera, el otro marcador de recambio óseo, la osteocalcina, no varió.

Los resultados encontrados en el grupo 3 (calcio) muestran un ligero aumento en la excreción de calcio urinario (de $5.0=0.1$ a $7.9=1.7, \mathrm{p} \quad 0.10$ ) igualmente hay un aumento en los niveles de fosfatasa alcalina.

Los resultados encontrados en el grupo 4 (placebo) no muestran ninguna variación, excepto un ligero aumento en la fosfatasa alcalina.
La fosfatasa alcalina total, como la medida en el presente trabajo, puede representar dos orígenes distintos: una fracción hepática y una fracción ósea (18). Esta última puede ser determinada por inmunoanálisis específicos con anticuerpos monoclonales que cada vez se perfeccionan más (29). De todas maneras es interesante el comportamiento de esta proteína enzimática no sólo por lo encontrado en los datos al inicio del estudio sino también por los cambios que se observan en los diferentes grupos de tratamiento y más concretamente en los grupos 1 y 2 .

Será necesario, antes de sacar cualquier conclusión, seguir observando este marcador de recambio óseo en el transcurso del tiempo que pareciera ser de gran utilidad, incluso más que la osteocalcina, es de fácil determinación en cualquier laboratorio y bastante económico.

\section{Conclusiones}

La excreción de calcio urinario está disminuida en las pacientes con OPPM sobre todo en los grupos de mayor edad, en donde también se encontraron los valores más altos de la PTH.

El metabolismo del fósforo no sufre mayores alteraciones en esta entidad.

La PTH está significativamente aumentada en las pacientes con OPPM, se correlaciona bien con la edad de la paciente y con el tiempo de evolución de la menopausia. Igualmente tuvo un comportamiento fisiológico esperado con respecto al metabolismo del calcio y fósforo. Finalmente, tiene una interacción con la fosfatasa alcalina, posiblemente inhibiendo su producción a nivel de la célula osteoprogenitora, puesto que se relaciona de manera inversa con ella.

Los marcadores de recambio óseo, osteocalcina y fosfatasa alcalina, están aumentados en las pacientes con OPPM y son una constante fisiopatológica en esta entidad. Se aumenta también con la edad de la paciente dejando entrever unos mecanismos de recambio óseo intactos.

No tienen ninguna relación con el estatus de función tiroidea. Con los niveles de gonadotropina (FSH) se correlacionan de manera inversa.

El índice de deformidad vertebral, planteado aquí, es un método sencillo y económico para medir el grado de compromiso óseo en la osteoporosis. Se relaciona bien con la edad de la paciente y con el tiempo de evolución de la menopausia.

Las vértebras con mayor compromiso fueron las de soporte de peso y gravedad.

El índice de deformidad tiene una relación inversa con los niveles de calcio sérico y urinario, hallazgo que traduce un mecanismo de defensa del organismo ante la pérdida progresiva de hueso y en el que posiblemente esté mediando la PTH.

No existe ninguna relación del grado de osteoporosis con el estado de función tiroidea y paratiroidea.

El grado de respuesta hipofisiario ante la menopausia está más intacto entre más joven sea la paciente, así como la producción hormonal ovárica de estradiol.

El nivel de calcio ingerido en la dieta está por debajo de las recomendaciones internacionales, aunque su posible mediación como factor de riesgo en cuestionable.

Los tratamientos empleados aquí tienen buena aceptabi- 
lidad y tolerancia por parte de las pacientes.

El fluoruro estimula la formación de hueso, evidenciado a través de un aumento en los marcadores de recambio óseo osteocalcina y fosfatasa alcalina.

La terapia secuencial hormonal (estrógeno + progestágeno) disminuye la excreción urinaria de calcio.

La fosfatasa alcalina tiene un comportamiento interesante tanto en los hallazgos iniciales del estudio como en los de seguimiento. Podría ser un útil, fácil y económico recurso de diagnóstico y evolución de la osteoporosis postmenopáusica.

\section{Agradecimientos}

Merck Colombia, Laboratorio Grunenthal, Schering Alemana, CIS-International (Francia), Ingeominas, Departamento de Farmacia, Facultad de Ciencias, Universidad Nacional, Departamento de Nutrición, Facultad de Medicina, Universidad Nacional.

\section{BIBLIOGRAFIA}

1. Cummings S, Kelsey J, Nevitt C, O'Dowd K. Epidemiology of osteoporosis and osteoporotio fractures. Epidem Rev 1985; 178-208.

2. Eastell R, Riggs L. Calcium homeostasis and osteoporosis. Endoc and Metab Clin N Am 1987; 16: 829-842.

3. Ernst M, Schmidt Ch, Froesch R. Enhanced osteoblast proliferation and collagen gene expression by estradiol. Proc Natl Acad Sci USA 1988; 85: 2307-2310.

4. Diczfaluzy E. Menopause, developing countries and the 21. st century. Acta Obstet Gynecol Scand (Suppl) 1986; 134: 45-57.

5. Anónimo. Osteoporosis: consensus conference. JAMA 1984; 252 799-802.

6. Ministerio de Salud de Colombia. Macroindicadores de Salud. Oficina de Planeación, División de Información. Bogotá, Minsalud, 1988.

7. Arnaud C, Sánchez S. The role of calcium in osteoporosis. Annu Rev Med 1990; 10: 397-414.

8. Bijvoet $\mathrm{O}$, Walton $\mathrm{R}$. Nomogram for derivation of renal threshold phosphate concentration. Lancet 1975; 2: 309-310.

9. Eastell R, Riggs L. Diagnostic evaluation of osteoporosis. Endoc and Metab Clin N Am 1988; 17: 547-571.

10. Norman G, Streiner D. PDQ statistios. BC Decker Inc., McMaster University, Toronto; 1986.

11. Schefler W. Bioestadística Fondo Educativo Panamericano, México; 1981.

12. Nordin BEC, Polley K. Metabolic consequences of the menopause. Calcif Tissue Int; 1987; 41 (suppl 1): 81-859.

13. Aurbach G, Marx S, Spiegel A. Parathyroid hormone, calcitonin and the calciferols. Textbook of endocrinology, 7th ed. Wilson J, Foster W eds., WB Saunders 1985; 1137-1217.

14. Sution R, Dirks J. Calcium and magnesium: renal handling and disorders of metabolism. The Kydney, 3th ed. Brenner B, Rector F eds., WB Saunders 1986; 619-662.

15. Broadus $\mathbf{A}$, Rasmussen $\mathrm{H}$. cinical evaluation of parathyroid function. Am J Med 1981; 70: 475-478.

16. Majeska R, Rodan G. Alkaline phosphatase inhibition by parathyroid hormone and isoproterenol in a clonal rat osteosarcoma cell line. Possible mediation by cyclic AMP. Calcif Tissue Int 1982; 34: 59-66.
17. Epstein $S$. Serum and urinary markers of bone remodeling: assessment of bone turnover. Endoc Rev 1988; 9: 437-444.

18. Robey P. The biochemestry of bone. Endoc and Metab Clin N Am 1989; 18: 859-902.

19. Faber J, Perrild H, Johansen J. Bone gla protein and sex hormone binding globulin in nontoxic goiter: parameters for metabolic status at the tissue level. J Clin Endoc Metab 1990; 70: 49-55.

20. Tam C, Heersche J, Murray T, Parsons $J$. Parathyroid hormone stimulates the bone apposition rate independently of its resorptive action: differential effects of intermitent and continuous administration. Endocrinology 1982; 110: 506-512.

21. Mundy G, Shapiro J, Bandelin J, Canalis E, Raisz L. Direct stimulation of bone resorption by thyroid hormones. J Clin Invest 1976; 58: $529-534$

22. Matckovic V, Kostial K, Simonovic I, Buzina R, Brodarec A, Nordin BEC. Bone status and fracture rates in two regions of Yugoslavia. Am J Clin Nutr 1979; 32: 540-549.

23. Bikle D. Fluoride treatment of osteoporosis: a new look at an old drug. Ann Int Med 1983; 98: 1013-1015.

24. Eriksen E. Normal and pathological remodeling of human trabecular bone: three dimensional reconstruction of the remodeling sequences in normals and in metabolic bone disease. Endoc Rev 1986; 7: 379-408.

25. Brown E. Fluoride and the therapy of osteoporosis. J Clin Endoc Metab 1989; 69: 929-931.

26. Vallach S, Avioli L, Carstens J. Factors in bone formation. Calcif Tissue Int 1989; 45: 4-6.

27. Lobo R, McCormick W, Singer F. Depomedroxyprogesterona acetate compared with conjugated estrogens for treatment of posmenopausal women. Obstet Gynecol 1984; 63: 1-5.

28. Prior J. Progesterone as a bone trophic hormone. Endoc Rev 1990; 11: 396-398

29. Duda R, O’Brien J, Katzmann J, Peterson J, Mann K, Riggs L. Concurrent assays of circulating bone gla protein and bone alkaline phosphatase: effects of sex, age, and metabolic bone disease. J Clin Endoc Metab 1988; 66: 951-957. 